\section{Bio-Numerical Analysis of the Human Ankle-Foot Model Corresponding to Neutral Standing Condition}

\author{
Darwich A. ${ }^{1 \oplus}$, Nazha H. ${ }^{2 * \odot}$, Nazha A. ${ }^{3}$, Daoud M.4, Alhussein A. ${ }^{5}$
}

\begin{abstract}
Background: The foot is the most complex body's structure; it is highly susceptible to disorders because of its loading pattern. The complexity of the foot structure geometry implies the use of reverse engineering tools to obtain a model that can accurately mimic the biomechanical behavior of the foot.

Objective: The objective of this study is to establish a state-of-the-art ankle-foot finite element (FE) model with anatomically realistic geometry and structure in order to get the model that will suit all cases for future studies on stress injuries and foot insole designs under different loading conditions.
\end{abstract}

Material and Methods: In this analytical study, tomography images were imported in DICOM format, after that, the object was exported in the form of threedimensional structures in STL file format to define and assemble the structures. After that, the computer simulation on numerical model was done. One-way Analysis of variance $($ ANOVA) test was performed, and a threshold $(p<0.05)$ was used to indicate the significance of results.

Results: The results showed no significant differences $(\mathrm{P}>0.05)$ between the values of the plantar pressure corresponding to neutral standing condition with other foot models in literature. The stresses transferred to the bone structure show that the relatively higher stress was located in the fifth, fourth and third tarsometatarsal, where the maximum von Mises stress in the bone structure was $2155.4 \mathrm{kPa}$.

Conclusion: The state-of-the-art ankle-foot FE model with anatomically realistic geometry and structure will be very helpful for future studies on stress injuries and foot insole designs under different loading conditions.

Citation: Darwich A, Nazha H, Nazha A, Daoud M, Alhussein A. Bio-Numerical Analysis of the Human Ankle-Foot Model Corresponding to Neutral Standing Condition. J Biomed Phys Eng. 2020;10(5):645-650. doi: 10.31661/jbpe.v0i0.2004-1094.

\section{Keywords}

Methods; Ankle; Foot; Stress Distribution; Neutral Standing

\section{Introduction}

$\mathrm{T}$ he standing posture is significant for human movement abilities to master the controls of it, which is a vital requirement for different daily physical activities [1]. However, the foot is an anatomically complicated structure with many movements and joints [2], where the foot contains 26 bones, 19 muscles, 33 joints and 107 ligaments. This constitutes $12 \%$ of the human body bones. These components work efficiently together to provide the human body with balance, support and mobility [3]. The foot is the most complex body's structure, and highly susceptible to disorders because of its loading pattern. The complexity
${ }^{1} \mathrm{PhD}$, Faculty of Bio-

medical Engineering,

Al-Andalus University

for Medical Sciences,

Tartous, Syria

${ }^{2}$ PhD, Faculty of Techni-

cal Engineering, Univer-

sity of Tartous, Tartous,

Syria

${ }^{3} \mathrm{BSc}$, Faculty of Me-

chanical and Electrical

Engineering, Damascus

University, Damascus,

Syria

${ }^{4} \mathrm{PhD}$, Technological

Research Institute Ma-

terials, Metallurgy and

Processes, Metz, France

${ }^{5} \mathrm{PhD}$, ICD-LASMIS, Uni-

versity of Technology of

Troyes, Nogent, France

*Corresponding author: H. Nazha

Faculty of Technical Engineering, University of

Tartous, Tartous, Syria

E-mail: hasannazha15@ gmail.com

Received: 2 April 2020 Accepted: 15 May 2020 
of the foot structure geometry implies the use of reverse engineering tools to obtain a model that can accurately mimic the biomechanical behavior of the foot [4].

It is worth pointing up that a sensor-embedded insole, wearing during physical activities, has been used to analyze standing postural because of its property degradation during physical activities. Previous research showed that many sensor-embedded insoles have been developed based on various sensing technologies [5]. For instance, the ParoTec system uses piezo-resistive sensors, the F-Scan system employs the force-sensing resistor (FSRs), and the Pedar system applies embedded capacitive sensors.

All of these systems have shown their practicability and capability to analyze standing postural. Nevertheless, these techniques suffer from some technical difficulties that could affect the measurement accuracy. In fact, the value of output may change due to the heat inside the shoes when the load is applied for a long period. In addition, the flexible contact surface could deform, resulting in a variation in the sensor's response [6-8].

Hence, the objective of this study is to establish a state-of-the-art ankle-foot FE model with anatomically realistic geometry and structure, and to compare the plantar pressure distribution corresponding to neutral standing condition with other foot models in literature in order to get the model that will suit all cases for future studies on stress injuries and foot insole designs under different loading conditions.

\section{Material and Methods}

\section{Modeling and meshing}

In this analytical study, building a threedimensional computer model based on computed tomography scans is the most accurate way to maintain the dimensions of the geometric studied structure without distortions or changes. The three-dimensional model of the compounding area was carried out according to the following stages that are summarized in Figure 1(a): Tomography images were imported in DICOM format. The minimum threshold was set at $-325 \mathrm{HU}$ and the upper at $-1000 \mathrm{HU}$. The foot area was then specified and the rest of the image was removed based on a region-growing algorithm, after that, the object was exported in the form of three-dimensional structures in STL file format. The numerical foot model was then exported to Autodesk $^{\circledR}$ Inventor ${ }^{\mathrm{TM}}$ software to define and assemble the structures. After that, Ansys ${ }^{\circledR}$ Workbench $^{\mathrm{TM}}$ software was used to perform computer simulation on numerical model.

The model was then subdivided into elements by volumetric meshing, where elements for FEA were tetrahedrons. The mesh was refined and accepted when the relative errors were less than 1\% [9-11], as shown in Figure 1(b). Before refining, the mesh consisted of 131268 nodes and 72675 elements as shown in Figure 2(a). After refining, the mesh consisted of 403308 nodes and 230887 elements as shown in Figure 2(b).

\section{Boundary conditions}

The patient details are given as follows: his gender is male with 29 years old having a body weight of $80 \mathrm{~kg}$ and a height of 180 $\mathrm{cm}$. The right foot is considered in this investigation with a length of $26.9 \mathrm{~cm}$. To simulate static standing conditions, the ground plate was bounded in all directions. The coefficient of friction between the plantar surface and ground was 0.6 [12]. The static loads have been applied on the plantar discrete locations [13]: hallux (HX) $594.5 \mathrm{kPa}$, metatarsal 1 (1M) $527.1 \mathrm{kPa}$, metatarsal 2 (2M) $469.3 \mathrm{kPa}$, metatarsal 3\&4 (3\&4M) $392.2 \mathrm{kPa}$, metatarsal $5(5 \mathrm{M}) 271.6 \mathrm{kPa}$, heel $(\mathrm{H}) 567.6 \mathrm{kPa}$ as shown in Figure 2(c).

\section{Material properties}

All the materials were idealized as isotropic and linear-elastic except for the soft tissues, defined as hyperelastic. The Young's 

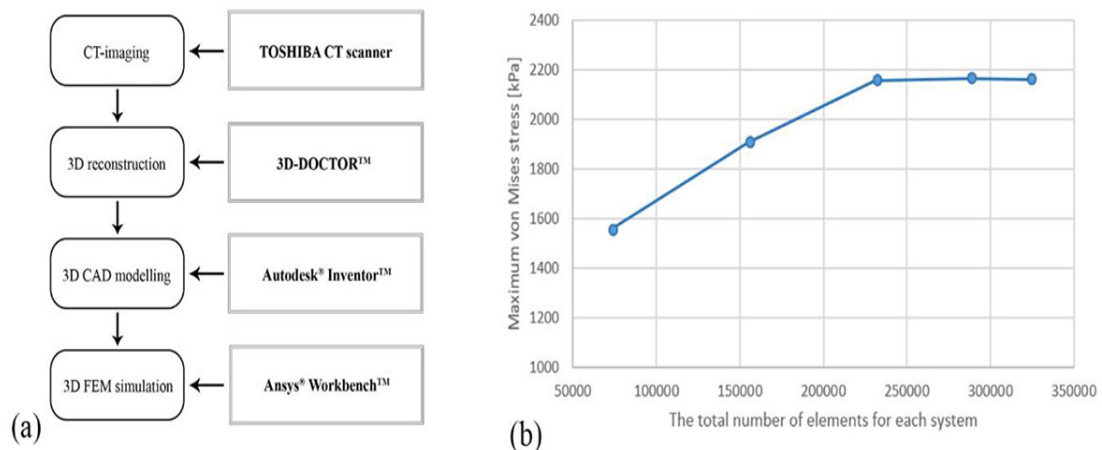

Figure 1: (a) The stages of 3D finite element (FE) model design, (b) Mesh sensitivity results in terms of the maximum von Mises stress.
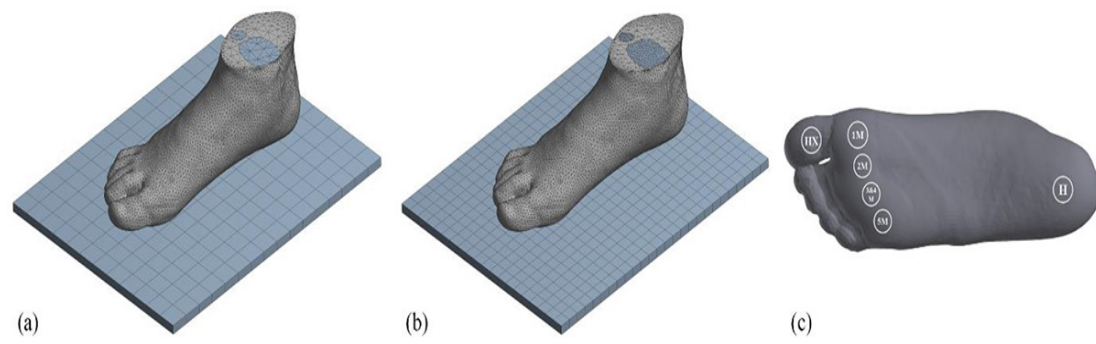

(c)

Figure 2: (a) 3D Mesh before refining, (b) 3D Mesh after refining, (c) Plantar discrete locations that subjected to standing loads.

modulus was defined as $7300 \mathrm{MPa}, 1 \mathrm{MPa}$, $350 \mathrm{MPa}, 260 \mathrm{MPa}$, and $17000 \mathrm{MPa}$ for the bony structure, cartilage, plantar fascia, ligament, and ground, respectively. The Poisson's ratio was defined as $0.3,0.4$ and 0.1 for the bony structure, cartilage and ground, respectively. The cross-section area was $58.6 \mathrm{~mm}^{2}$ and $18.4 \mathrm{~mm}^{2}$ for the plantar fascia and ligament. The parameters of encapsulated soft tissue of the finite element model were defined as $\mathrm{C}_{10}=0.0855, \mathrm{C}_{01}=-0.0584, \mathrm{C}_{20}=0.0390$, $\mathrm{C}_{11}=-0.0231, \mathrm{C}_{02}=0.0085, \mathrm{D}_{1}=3.6527$. All the reference values were taken from the literature [14-20]. Non-linear biaxial, shear and uniaxial mechanical behavior of the encapsulated soft tissues are shown in Figure 3.

Statistical analysis

The plantar pressure values corresponding to neutral standing condition in comparison with other foot models in literature were used to assess the variability of the results. One-way
ANOVA test was performed, and a threshold $(p<0.05)$ was used to indicate the significance of results using IBM SPSS ${ }^{\circledR}$ Statistics V26 [21].

\section{Results}

The data acquired from the FE analysis can be presented in a map with a color scale, which could help to compare the stresses for the models. For the validation of the anklefoot model, Figure 4(a) shows that the stress distribution and the peak value were in a good agreement with experimental one reported in the literature, even if relatively higher stresses are located in the forefoot and rearfoot. The stress distribution in current FE model was also compared to those from other numerical data reported in the literature as shown in Figure 4(b), where the comparison shows a good agreement in the patterns of predicted and measured stress distribution and the peak 


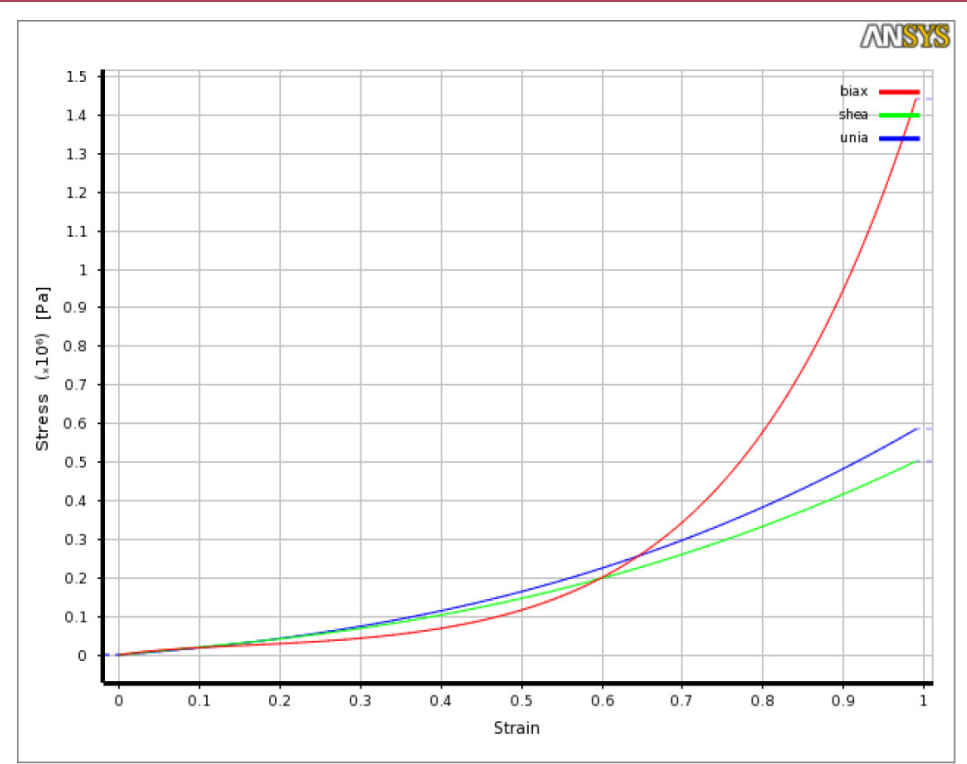

Figure 3: Encapsulated soft tissues biaxial, shear and uniaxial mechanical behavior.

(a)

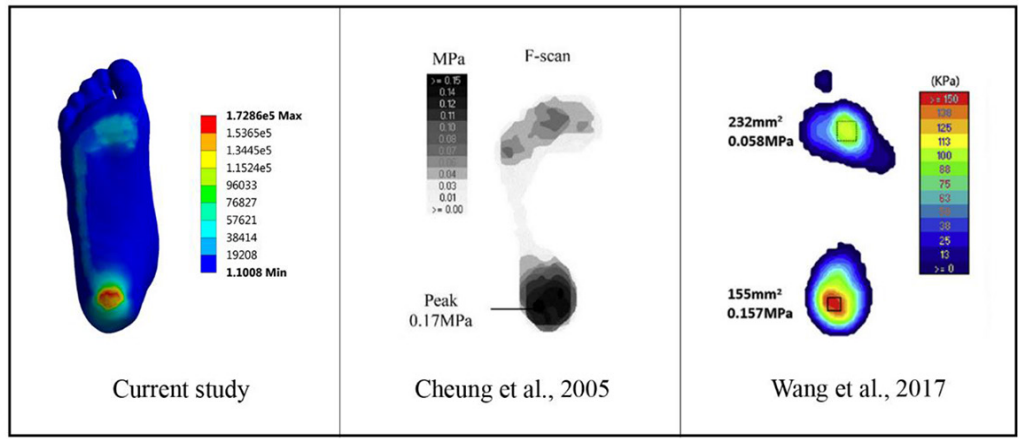

(b)

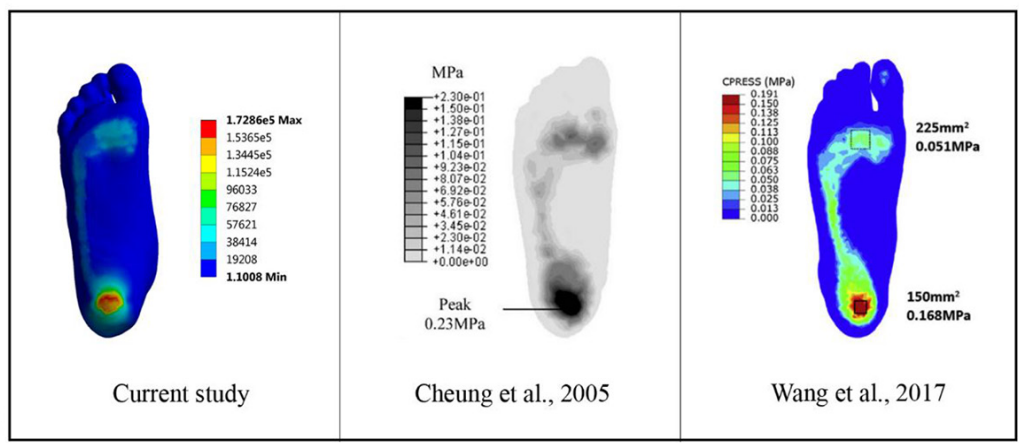

Figure 4: Comparison of predicted plantar pressure (Pa): (a) with published experimental data, (b) with published numerical data.

value during balance standing condition.

From Table 1, ANOVA results showed no significant differences $(\mathrm{P}>0.05)$ between the values of the plantar pressure corresponding to neutral standing condition with other foot models in literature. The stresses transferred to the bone structure show that the relatively higher stress was located in the fifth, fourth and third tarsometatarsal as shown in Figure 5, where the maximum von Mises stress in the 
Analysis of the Human Ankle-Foot Model

Table 1: Analysis of variance (ANOVA) results of von Mises stress for the soft tissue.

\begin{tabular}{cccc} 
& Mean & Standard deviation & Standard error \\
\hline Current model & 0.172 & 0.0028 & 0.002 \\
\hline Cheung et al. model & 0.2 & 0.0424 & 0.03 \\
\hline Wang et al. model & 0.1625 & 0.0078 & 0.0055 \\
\hline F-statistics & & 1.22184 & \\
\hline P-value & & 0.40911
\end{tabular}

bone structure was $2155.4 \mathrm{kPa}$.

\section{Discussion}

Planar pressure distribution on the plantar foot is one of the most common method to analyze the postural sway and body stability. Finite element analysis is a useful method to understand the distribution mechanisms of the loads under the foot [22-24]; it can be also a powerful method to understand the foot biomechanical behavior and its influence on human comfort generation.

In order to achieve reliable data in current study, three basic verifications were made; first, to ensure about the mesh size, a sensitivity analysis of the mesh was performed, where it was accepted when the relative errors were $<1$ percentage as previously mentioned. Second, a comparison with respect to related previous works $[16,25]$, as we stated in this study. Third, performing an analysis of variance where the results showed no significant
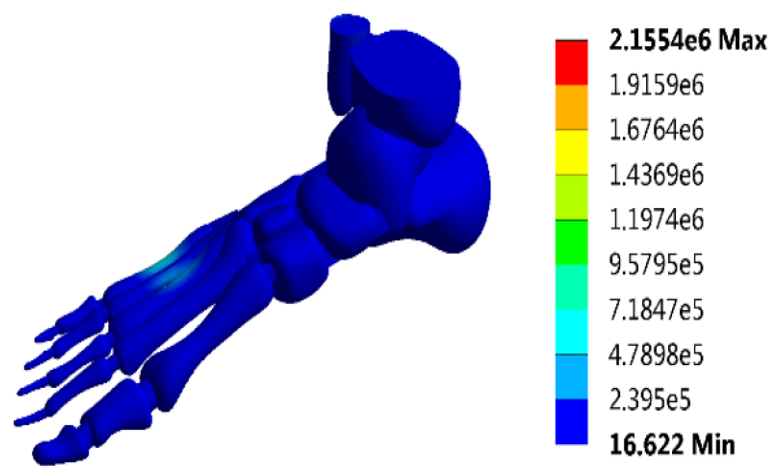

Figure 5: Stress transferred to the bone structure $(\mathrm{Pa})$. differences $(\mathrm{P}>0.05)$ between the values of the plantar pressure corresponding to neutral standing condition with other foot models in literature.

Many researchers studied the kinematics of foot reaction to the ground using finite element analysis first, so that their parameters are verified and validated before going on to the actual experiment. This non-linear finite element model was purposed as a tool for the design optimization process of shoe insoles. Thus, the details of human foot model were generated from computed tomography scan image data using segmentation rebuilding techniques and 3D-CAD modelling. After that, a wide variety of insole materials and geometries can be tested so as to study the comfort behavior through the modification of insole materials definition and/or insole geometrical design.

\section{Conclusion}

The finite element modeling process and method in the current study are satisfactory and practical based on the predicted numerical results for validation of the model. Hence, the state-of-the-art ankle-foot FE model with anatomically realistic geometry and structure will be very helpful for future studies on stress injuries and foot insole designs under different loading conditions.

\section{Acknowledgment}

The authors would like to thank William Abbas (Faculty of Mechanical Engineering, Czech Technical University, and Prague, Czech Republic) for his support. 


\section{Conflict of Interest}

None

\section{References}

1. Massion J. Postural control system. Curr Opin Neurobiol. 1994;4(6):877-87. doi: 10.1016/09594388(94)90137-6. PubMed PMID: 7888772.

2. Antunes PJ, Dias GR, Coelho AT, Rebelo F, Pereira T. Non-linear finite element modelling of anatomically detailed 3D foot model. Report paper. 2008:1.

3. France DL. Human and nonhuman bone identification: a color atlas. CRC Press; 2008. p. 584.

4. Porter DA, Schon LC. Baxter's the Foot and Ankle in Sport. Elsevier Health Sciences; 2020. p. 624.

5. Abdul Razak AH, Zayegh A, Begg RK, Wahab Y. Foot plantar pressure measurement system: A review. Sensors. 2012;12(7):9884-912. doi: 10.3390/s120709884. PubMed PMID: 23012576. PubMed PMCID: PMC3444133.

6. Brimacombe JM, Wilson DR, Hodgson AJ, Ho KC, Anglin C. Effect of calibration method on Tekscan sensor accuracy. J Biomech Eng. 2009;131(3):034503. doi: 10.1115/1.3005165. PubMed PMID: 19154074.

7. Hurkmans HL, Bussmann JB, Selles RW, Horemans HL, Benda E, Stam HJ, Verhaar JA. Validity of the Pedar Mobile system for vertical force measurement during a seven-hour period. Journal of Biomechanics. 2006:39(1):110-8. doi: 10.1016/j.jbiomech.2004.10.028. PubMed PMID: 16271594.

8. Woodburn J, Helliwell PS. Observations on the F-Scan in-shoe pressure measuring system. Clin Biomech (Bristol, Avon). 1996;11(5):301-4 doi: 10.1016/0268-0033(95)00071-2. PubMed PMID: 11415636.

9. Shash M, Nazha H, Abbas W. Influence of different abutment designs on the biomechanical behavior of one-piece zirconia dental implants and their surrounding bone: a 3D-FEA. IRBM. 2019:40(6):313-9. doi: 10.1016/j. irbm.2019.07.001.

10. Živaljić N, Smoljanović H, Nikolić Ž. Sensitivity analysis of numerical parameters in FEM/DEM model for RC structures. International Journal for Engineering Modelling. 2012;25(1-4):7-17.

11. Darwich A, Nazha H, Daoud M. Effect of Coating Materials on the Fatigue Behavior of Hip Implants: A Three-dimensional Finite Element Analysis. Journal of Applied and Computational Mechanics. 2020;6(2):284-95. doi: 10.22055/ JACM.2019.30017.1659.

12. Zhang M, Mak AF. In vivo friction properties of human skin. Prosthet Orthot Int. 1999;23(2):13541. doi: 10.3109/03093649909071625. PubMed PMID: 10493141.

13. Abu-Faraj ZO, Harris GF, Chang AH, Shereff MI. Evaluation of a rehabilitative pedorthic: plantar pressure alterations with scaphoid pad applica- tion. IEEE Trans Rehabil Eng. 1996;4(4):32836. doi: $10.1109 / 86.547934$. PubMed PMID: 8973959.

14. Nakamura S, Crowninshield RD, Cooper RR. An analysis of soft tissue loading in the foot--a preliminary report. Bulletin of Prosthetics Research. 1981;10:27-34. PubMed PMID: 7332829 .

15. Gefen A, Megido-Ravid M, Itzchak Y, Arcan M. Biomechanical analysis of the three-dimensional foot structure during gait: a basic tool for clinical applications. J Biomech Eng. 2000;122(6):6309. doi: 10.1115/1.1318904. PubMed PMID: 11192385

16. Wang Y, Li Z, Wong DWC, Cheng CK, Zhang M. Finite element analysis of biomechanical effects of total ankle arthroplasty on the foot. Journal of Orthopaedic Translation. 2017;12:55-65. doi: 10.1016/j.jot.2017.12.003

17. Wright DG, Rennels DC. A study of the elastic properties of plantar fascia. J Bone Joint Surg Am. 1964;46:482-92. PubMed PMID: 14131427.

18. Qiu TX, Teo EC, Yan YB, Lei W. Finite element modeling of a 3D coupled foot-boot model. Medical Engineering \& Physics. 2011;33(10):122833. doi: 10.1016/j.medengphy.2011.05.012. PubMed PMID: 21676642.

19. Athanasiou KA, Liu GT, Lavery LA, Lanctot DR, Schenck JR. Biomechanical topography of human articular cartilage in the first metatarsophalangeal joint. Clinical Orthopaedics and Related Research. 1998:269-81. PubMed PMID: 9553561.

20. Cheung JT, Zhang M. Parametric design of pressure-relieving foot orthosis using statisticsbased finite element method. Med Eng Phys. 2008;30(3):269-77. doi: 10.1016/j.medengphy.2007.05.002. PubMed PMID: 17584519.

21. Dar FH, Meakin JR, Aspden RM. Statistical methods in finite element analysis. J Biomech. 2002;35(9):1155-61. doi: 10.1016/s00219290(02)00085-4. PubMed PMID: 12163305.

22. Luo G, Houston VL, Garbarini MA, Beattie AC, Thongpop C. Finite element analysis of heel pad with insoles. J Biomech. 2011;44(8):1559-65. doi: 10.1016/j.jbiomech.2011.02.083. PubMed PMID: 21420682.

23. Hsu YC, Gung YW, Shih SL, Feng CK, Wei SH, $\mathrm{Yu} \mathrm{CH}$, Chen CS. Using an optimization approach to design an insole for lowering plantar fascia stress - a finite element study. Ann Biomed Eng. 2008;36(8):1345-52. doi: 10.1007/s10439-0089516-x. PubMed PMID: 18481179.

24. Mandolini M, Germani M, Raffaeli R. A Finite Element Method to support the materials selection phase during the insole design process. Madrid: XXIII International Conference on Graphic Engineering; 2013.

25. Cheung JT, Zhang M. A 3-dimensional finite element model of the human foot and ankle for insole design. Arch Phys Med Rehabil. 2005;86(2):3538. doi: 10.1016/j.apmr.2004.03.031. PubMed PMID: 15706568. 